\title{
HISTÓRIA E MEMÓRIA EDUCACIONAL: A IMPORTÂNCIA DOS ARQUIVOS E CENTROS DE DOCUMENTAÇÃO*
}

\author{
Antonia Marlene Vilaca
}

\section{INTRODUÇÃO}

A importância dos Arquivos e Centros de Documentação na preservação de Acervos da História e Memória Educacional, ainda é pouco difundido entre nós e o entendimento acerca da preservação de acervos ocorre até mesmo no interior das universidades. No Brasil a partir da Constituição de 1988 e no processo de redemocratização da sociedade se estabeleceu novas possibilidades de acesso às informações e preservação dos dados históricos. Porém o acesso aos arquivos documentais permanece em descompasso com os princípios consagrados na legislação, seja pelas políticas oficiais de restrição, seja pelo pouco conhecimento acerca dos avanços propiciados pela legislação específica, seja pela falta de apoio orçamentário.

Pesquisar em arquivos tem sido uma atividade dura e desafiadora tarefa que exige muita paciência do pesquisador. $O$ trabalho do pesquisador via de regra consiste na busca de papéis desorganizados cabendo a ele descobrir onde localizá-los. Nesta empreitada muitas vezes é preciso superar obstáculos de ordem burocrática, da capacitação do atendente na localização dos arquivos e da falta de formação adequada daqueles que deveriam facilitar o trabalho do pesquisador. No Brasil as políticas de arquivos são regulamentadas mediante um arcabouço legal estando presente na Constituição Federal, decretos, portarias, resoluções, legislações estadual e municipal e instruções normativas. A Lei no. 8.159, de 08 de janeiro de 1991 dispõe sobre a Política Nacional de Arquivos Públicos e Privados considerando-os em seu Art. 2o:

Os conjuntos de documentos produzidos e recebidos por órgãos públicos, instituições de caráter público e entidades privadas, em decorrência do exercício de atividades específicas, bem como por pessoa física, qualquer seja o suporte da informação ou a natureza dos documentos (BRASIL, 1991).

"DOI - 10.29388/978-65-86678-77-2-0-f.10-21 
Porém, a realidade brasileira apesar de todo o aparato legal, na prática os arquivos institucionais de universidades, entidades e escolas continuam em sua grande maioria estão localizados em locais inapropriados, em depósitos de documentos os quais nem sempre se encontram organizados, sinalizados e bem-acondicionados. Dificultando o acesso aos documentos para consultas administrativas quem dirá então para algum levantamento de pesquisa histórico-científica.

Nesse sentido, este capítulo tem como objetivo, pontuar os elementos históricos e legais que envolvem a organização e acesso aos arquivos e centros de documentação, abordando a necessidade de organização dos arquivos públicos, considerando seu valor administrativo, político e histórico. A organização e sistematização dos arquivos das instituições escolares contribuirão para as pesquisas no campo da História da Educação no Brasil.

\section{ELEMENTOS METODOLÓGICOS NA ANÁLISE DOCUMENTAL E ELEMENTOS HISTÓRICOS SOBRE A PRESERVAÇÃO DE ARQUIVOS DOCUMENTAIS}

Adam Shaff (1995), ao indagar a razão de sempre estarmos reescrevendo a história considera que este processo se deve basicamente em função das necessidades do presente e dos efeitos dos acontecimentos do passado no presente. Os registros históricos são peças usadas pelos historiadores para produzir determinadas explicações históricas. A qualidade do conhecimento histórico depende da relação dos pesquisadores com as fontes e uma relação mais sólida com as fontes, só vai ser possível, quando, o pesquisador não precisar gastar boa parte do seu tempo de pesquisa, na localização dos arquivos.

Além do próprio ofício do pesquisador, imbuído de uma temática específica, um objeto de pesquisa, ele ainda precisa, ser um "arqueólogo documental" um caçador de documentos. Isso porque nem sempre suas fontes de pesquisa estão organizadas, sinalizadas, dispostas em prateleiras, pastas ou gavetas. Isso é o que apontam as diversas pesquisas realizadas nas universidades brasileiras, as quais trazem o relato de pesquisadores que além de realizar a localização das fontes primárias, tiveram ainda que fazer a catalogação das mesmas. Isso revela a precariedade dos arquivos e centros de documentação brasileiros e é uma preocupação para a qualidade das pesquisas futuras.

O historiador Eric Hobsbawm (1998, p. 23 e 30), ao afirmar que "O passado é, portanto, uma dimensão permanente da consciência humana, um componente inevitável das instituições, valores e outros padrões da sociedade 
humana", aponta a pesquisa histórica, como ferramenta analítica para analisar o passado sendo útil no processo de análise das mudanças constantes. Assim, as fontes documentais são para o pesquisador a lente pela qual ele olha o passado e pode fazer a sua análise e interpretação.

Um dos desafios das pesquisas na área da memória histórica para o pesquisador tem sido a dificuldade de encontrar arquivos e centros de documentação com material organizado e disponível para as pesquisas, o que suscita nas recomendações insistentes, para a criação das condições objetivas para a preservação das fontes que possibilitem buscar explicitar a singularidade na relação Estado e sociedade. A pesquisa historiográfica está sujeita ao pesquisador já em seu primeiro momento, na sua escolha de temática, em sua metodologia de pesquisa, em suas diretrizes de busca, no levantamento das fontes o pesquisador, como bem nos lembra Maria Elisabeth Blanck Miguel (2004, p. 116) "a amplitude do olhar do pesquisador se dá ao levantar as fontes. Aí ele não identifica apenas objetos específicos, mas descobre outras questões sociais que demarcam um período", nesse sentido, no trabalho de reconstrução histórica, a relação do pesquisador com as fontes sob análise interpretativa do momento histórico-social.

Podemos dizer que na pesquisa científica, não existe neutralidade, por parte do pesquisador (nem por parte da fonte/documento histórico), isso porque na medida em que ele expressa interesses político-ideológicos, compromissos profissionais e acadêmicos na sua formação, e do documento, porque ele faz parte de um processo que o construiu e também o preservou. 0 referencial para analisar se há ou não neutralidade está na realidade social. Partindo do pressuposto de que a sociedade é constituída por classes sociais desiguais e antagônicas, podemos concluir que o conhecimento, a ciência, a educação são frutos do seu tempo, são situados historicamente e socialmente constituídos. Caberá ao pesquisador não ser ingênuo ao depositar total confiança nos documentos e fontes; ele deve questionar as fontes e os documentos, na medida em que a história tem sido contada, geralmente na perspectiva da classe dominante, ocasionalmente, ou podemos até afirmar que quase sempre, os documentos guardados em determinados períodos históricos, foram selecionados para posteridade, assim como, o próprio pesquisador carrega consigo, suas convicções, suas ideologias e até seus malentendidos.

Desde a antiguidade a sociedade humana vem organizando a sua memória, interagindo produzindo e acumulando conhecimentos, por meio de suas práticas socais. O registro desse conhecimento pode ser percebido mediante das diversas maneiras que, historicamente, se utilizou para registrar e conservar suas atividades e saberes por meio de pintura em cavernas, os 
entalhes, os objetos diversos utilizados como suportes de informações. A grande quantidade de registros, aliados aos problemas de preservação, fez com que fosse necessário abrigar e organizar esses materiais. O surgimento dos espaços físicos, denominados de Arquivos, nasceram da necessidade de guardar, organizar e conservar os registros diversos que a sociedade produz sobre si mesma.

Desde suas origens os arquivos tiveram essa função de armazenar os documentos, sobretudo, de reunir e conservar um dossiê da administração do Rei, Monarca ou governante. Isso com o intuito de preservar os documentos comprobatórios de sua autoridade, seus interesses e direitos. Os arquivos e bibliotecas na Idade Média passaram a ser monopolizados pela Igreja, tornando o acesso restrito a poucos. Foi somente a partir da Revolução Francesa, com o interesse de consolidar o Estado Nacional, que se incrementou a criação dos chamados arquivos nacionais.

No século XIX, há uma verdadeira "explosão" da informação. O progresso científico e tecnológico implementou a produção informacional e com o advento da imprensa impulsionou o processo de "socialização" das informações. Nesse período, também os documentos escritos ganham status de testemunho histórico. O século XIX, considerado o "século da história", legitimou o saber histórico como "ciência", tornando-a disciplina especializada, produzida e ensinada nas universidades, a começar na Alemanha, com Leopold Von Ranke o qual priorizava o método científico na pesquisa histórica e o uso prioritário das fontes primárias. Nesse processo a heurística, torna-se a "pedra de toque" do trabalho do historiador (GRAFTON, 1998).

No século XX, principalmente após a Segunda Guerra Mundial, muitos arquivos e museus nacionais foram criados para legitimar a autodeterminação dos novos países independentes. A própria informatização, crescente e acelerada da sociedade a partir da segunda metade do século XX trouxeram novos problemas (e novas soluções) para os arquivos. Nesse processo complexo emerge uma nova ciência: a Ciência da informação ${ }^{1}$.

Essas considerações incorporadas à legislação brasileira sobre arquivos, em vigor desde 1991, direcionam a realidade atual da produção documental oficial, por meio de uma gestão documental na qual, obrigatoriamente, é submetida por conjuntos de procedimentos e operações técnicas referentes desde sua produção, tramitação, uso avaliação e arquivamento. Todo esse

\footnotetext{
${ }^{1}$ A Ciência da informação é o campo científico da arquivologia que gerencia as bibliotecas, arquivos e museus. Em consequência do progresso científico e tecnológico, a produção de documentos cresceu de forma a superar a capacidade de controle e organização das instituições, que se viram obrigadas a buscar soluções para gerir as grandes massas documentais, acumuladas como em nenhuma época anterior.
} 
procedimento determinado em lei, tem como propósito a organização da documentação, assim também como sua eliminação ou recolhimento para a guarda permanente.

\section{POLÍTICA E LEGISLAÇÃO ARQUIVÍSTICA: ARQUIVOS E CENTROS DE DOCUMENTAÇÃO BRASILEIROS}

A Lei Federal número 8.159, de 8 de janeiro de 1991, vem dotar o Brasil de uma política nacional para os arquivos públicos e privados, ficando a cargo do Conselho Nacional de Arquivos (CONARQ), órgão vinculado ao Arquivo Nacional, definir uma política, como órgão Central do Sistema Nacional de Arquivos $^{2}$. O CONARQ possibilitou a simplificação e a racionalização dos procedimentos utilizados pelas instituições, bem como a redução dos custos administrativos. A partir do momento em que há orientação, aperfeiçoamento e aproveitamento de recursos humanos e materiais, o desenvolvimento de atividades participativas e a adoção de um comportamento ético na gerência da coisa pública, o Estado e a sociedade convergem à responsabilidade de preservar o patrimônio arquivístico brasileiro e garantir o direito democrático à informação.

De acordo com Heloísa Liberalli Belloto (1991), o interesse em organizar arquivos responde diretamente a quatro tipos fundamentais de público: 1) o administrador, aquele mesmo que o produz e necessita dele; 2) o cidadão interessado em testemunhos que comprovem seus direitos para com o Estado; 3) o pesquisador acadêmico, seja ele historiador, sociólogo ou outro profissional em busca de informações para a análise do passado humano, em sociedade, seja ainda o estudioso em geral; 4) o cidadão comum, não interessado em dados jurídicos ou pesquisas acadêmicas, mas todo aquele que demanda uma cultura geral (BELLOTTO, 1991, p. 19).

\footnotetext{
${ }^{2}$ Vinculado ao Arquivo Nacional, o Conselho Nacional de Arquivos - CONARQ, órgão central do Sistema Nacional de Arquivos - SINAR, foi criado pelo art. 26 da Lei no 8.159, de 8 de janeiro de 1991, que dispõe sobre a política nacional de arquivos públicos e privados. De acordo com esta lei, as ações com vistas à consolidação da política nacional de arquivos deverão ser emanadas do CONARQ, cujas competências, organização e funcionamento são objeto do Decreto no 1.173 , de 29 de junho de 1994. Dentre as suas competências, merecem destaque: definir normas gerais e estabelecer diretrizes para o pleno funcionamento do Sistema Nacional de Arquivos - SINAR visando à gestão, à preservação e ao acesso aos documentos de arquivo"; "estimular programas de gestão e de preservação de documentos produzidos e recebidos por órgãos e entidades, no âmbito federal, estadual e municipal, em decorrência das funções executiva, legislativa e judiciária"; "estimular a implantação de sistemas de arquivos nos poderes Legislativo e Judiciário, bem como nos Estados, no Distrito Federal e nos Municípios".
} 
A Constituição da República Federativa do Brasil de 1988, no capítulo dos direitos e deveres individuais e coletivos, assegura o acesso à informação e resguarda o sigilo da fonte, quando necessários. A lei aponta ainda que todos têm o direito de receber dos órgãos públicos informações de seu interesse, seja ele particular ou coletivo. A lei também prevê que é responsabilidade da União, Estado e Município, o cuidado com a documentação e demais bens de valor histórico, artístico e cultural.

De acordo com a Lei Federal de Arquivos no 8.159, de 1991, que dispõe sobre a política nacional de arquivos públicos e privados e dá outras providências, afirma que é dever do Poder Público a gestão documental e a proteção especial a documentos de científico e como elementos de prova e informação. Na prática os arquivos públicos são os conjuntos de documentos produzidos e recebidos, no exercício de suas atividades, por órgãos públicos de âmbito federal, estadual, do Distrito Federal e municipal.

A legislação aponta também que o Arquivo Público deve ser entendido como a instituição do Poder Público com a função de implementar, acompanhar e supervisionar a gestão de documentos produzidos e recebidos pela Administração Pública em seu âmbito de atuação, e de promover a organização, a preservação e o acesso dos documentos de valor permanente ou histórico recolhidos dos diversos órgãos e entidades dos estados, do Distrito Federal e dos municípios.

O arcabouço legal que regulamenta a organização e acesso aos arquivos, é extenso e criterioso, no que diz respeito, a questão de deveres e obrigações que a esfera governamental deve dispensar no que tange à preservação oficial e histórica documental em todo o território nacional. As instituições que tem documentos sob sua guarda tem especificidades distintas, diferenciando-se por suas características e natureza e ao tratamento técnico empregado. Assim os espaços físicos, Arquivos, Centros de Documentação e Bibliotecas convergem em um ponto que é o atendimento ao público, seja ele, na maioria das vezes, o pesquisador, acadêmico ou "leigo". A instrumentalização dessas instituições, proporciona acesso à informação da maneira mais racional, eficaz e eficiente. A abertura ao público, ao cidadão, tem a finalidade de tornar o documento acessível às pessoas, democratizando o direito à informação.

No Brasil desde os anos 1970, os arquivos vêm se constituindo dentro e fora das universidades; nascem e se consolidam com a clara política de preservar documentos de origens diversas, testemunhos de grupos, de 
instituições, de personalidades e de "gente comum". Em suma, sua principal função tem sido a de guardar e difundir informações para a pesquisa histórica ${ }^{3}$.

Os Centros de Documentação e Pesquisa surgem na década de 1970, vinculados aos cursos de História de diversas universidades públicas. Em sua maioria, aparecem com o objetivo de preservação da memória e patrimônio histórico local ou regional, segundo a área de abrangência de cada universidade, como órgão de apoio à pesquisa. Segundo Marilena Leite Paes (1997), os Centros de Documentação ou Informação, abrangem algumas atividades próprias da biblioteconomia, da arquivística e da informática. Seu campo é pluridisciplinar e mais amplo, o que exige maior especialização na gestão de documentos de toda espécie.

Para Célia Reis Camargo (1999), os centros de Documentação das universidades são voltados à geração de informações e organização de fontes de pesquisa. Desde os anos setenta, ao lado da docência e da pesquisa, esse campo de trabalho tem se expandido cada vez mais. Entretanto, a existência desses centros, como dissemos, ultrapassa o universo acadêmico. Percebemos sua presença nas fundações culturais, museus, bibliotecas e instituições de pesquisa. Muitas empresas, inclusive, recrutam historiadores para a criação de centros de memória e documentação. Ainda que essas empresas possuam bibliotecas e arquivos, os profissionais da área de história e de arquivística são chamados a auxiliar as atividades referentes à base de informações, apoio da administração, da comunicação ou como instrumentos de decisão.

No interior das universidades, os Centros de documentação têm características fundamentais em relação à proposta de trabalho que se propõe a desenvolver como Camargo (1999) apresenta:

O trabalho dos centros de documentação envolve a reunião, preservação e a organização de arquivos e coleções (geralmente compostos por documentos originais, 'as fontes primárias') e de conjuntos diversos (de natureza bibliográfica ou arquivística, originais ou cópias) reunidos sob critério do valor histórico e informativo, em torno de tema ou de períodos da história (CAMARGO, 1999, p. 50).

Quando esses acervos se encontram organizados e disponibilizados à consulta, são suporte para as pesquisas realizadas por docentes e alunos da comunidade acadêmica. Como resultado desse trabalho, a finalidade é ampliar

\footnotetext{
${ }^{3}$ A finalidade dos Centros de Documentação é armazenar, classificar, selecionar e disseminar a informação. Mas também essa finalidade pode variar de acordo com os propósitos da criação dos Centros de Documentação e segundo suas linhas de pesquisa. De acordo com as características físicas do documento, cada tipologia receberá um tratamento específico, no sentido de conservá-lo e preservá-lo.
} 
o alcance dos serviços prestados aos demais segmentos sociais, com o interesse em atingir os usuários em potencial, ou seja, aqueles interessados em fazer usos dessas informações disponíveis. As atividades dos centros podem-se desdobrar em extensão universitária, o que proporcionaria novos usuários e pesquisadores e principalmente estar em contato com instituições congêneres, contribuindo com a política de preservação do patrimônio cultural do país. A existência dos Centros de Documentação Universitários desempenha um papel fundamental: que é o de ampliar as possibilidades de exercício da cidadania, servindo de base para a produção do conhecimento científico, proporcionando o acesso democratizado à informação especializada.

Além da questão da organização sistematizada, a autora ainda para alguns problemas que atingem os centros de documentação e memória, a importância da definição das linhas de acervo, as quais orientarão a atividade estrategicamente e a organização das bases informacionais do conhecimento, cumprindo sua finalidade em dar apoio informacional ao pesquisador assim como aproximar o pesquisador das fontes históricas.

Nesse sentido, a preservação e a conservação são objetivos fundamentais para o desenvolvimento das atividades práticas e cotidianas seja de um arquivo ou de um centro de documentação. As políticas de preservação consistem em assegurar as atividades de acondicionamento, armazenamento, conservação e restauração de documentos. Esta prática baseia-se num conjunto de procedimentos e medidas destinadas a assegurar a proteção física dos acervos ou arquivos contra os agentes de deterioração, que podem ser internos ou externos. Assim sendo, o ato de recolher os documentos em arquivos ou centros de documentação, sem atentar para uma organização sistematizada e racional, não transforma o documento em fonte de informação.

\section{HISTÓRIA DA EDUCAÇÃO NO BRASIL: FONTES DOCUMENTAIS E A PESQUISA EDUCACIONAL NO OESTE NO PARANÁ}

Como campo de pesquisa, a História da Educação está consolidada como disciplina científica específica, a qual se organizou e se articulou pela expressiva produção de pesquisas por investigadores em todo o Brasil, em grupos de estudos, linhas de pesquisa em cursos de pós-graduação e também pela criação de Centros de Memória da Educação.

A História da Educação no Brasil, tem os arquivos das instituições escolares, como referencial das fontes históricas para suas pesquisas, a partir da interpretação e análise da documentação que está em seus acervos. De acordo com Dermeval Saviani (2013), as instituições escolares fornecem as 
principais linhas de investigação no campo da História da Educação. As instituições escolares brasileiras trazem em si mesmas a sua própria história, sua origem e trajetória institucional, inseridas no contexto histórico local, regional e nacional. Assim, cabe ao historiador a função de interpretar os resultados contidos na documentação histórica fornecida nos arquivos escolares assim como, analisar o contexto em que essa produção documental aconteceu.

Como bem nos lembra Maria Elisabeth Blanck Miguel (2004, p. 116) "a amplitude do olhar do pesquisador se dá ao levantar as fontes. Aí ele não identifica apenas objetos específicos, mas descobre outras questões sociais que demarcam um período", nesse sentido, no trabalho de reconstrução histórica, é fundamental a relação do pesquisador com as fontes além de sua atenta análise interpretativa do momento histórico-social de guarda e produção documental. $O$ pesquisador não deve ter a confiança cega nos documentos e fontes, mas questionar as fontes e os documentos, considerando que na medida em que a história tem sido contada, geralmente, na perspectiva da classe dominante.

Ainda sobre a questão da fonte de pesquisa/documento, ele carrega em si mesmo, sua bagagem subjetiva, Jaques Le Goff (1994) em História e Memória, nos lembra que os resquícios do passado não é qualquer escolha e sim, resultado produzido das relações das forças que detinham o poder na sociedade.

A pesquisa historiográfica sobre a História da Educação tem sido realizada em todo o país, numa tarefa de preservação da memória histórica educacional. Os pesquisadores brasileiros realizam seu trabalho na produção do conhecimento científico, por meio de pesquisas históricas, preservando e resgatando a memória histórica das instituições escolares, preservando a história da educação. Essas pesquisas apontam também as dificuldades em localizar a documentação, o que lhes acarreta a tarefas de organização do material a ser pesquisado.

No oeste paranaense não é diferente essa situação, em que arquivos institucionais ainda são tratados como depósitos de papéis. Nem sempre sendo negligência da instituição escolar, mas, o que se verifica é a falta de suporte por parte da esfera governamental no que diz respeito à legislação arquivística brasileira. Falta também além da conscientização da necessidade da organização e preservação documental de ambas as partes, principalmente, recursos orçamentários, assegurando a contratação de profissionais da área arquivística e história, assim como material e a definição de espaços adequados e específicos para os arquivos institucionais. 
A pesquisa, levantamento de fontes em arquivos e instituições escolares no oeste do Paraná, tem contribuído para a preservação da memória histórica da educação e das instituições escolares. Exemplo disso, são as coletâneas "História da educação: pesquisa e memória histórica" (2008) e a "Coleção História da Educação: pesquisa, levantamento de fontes e instituições escolares", organizadas pelos pesquisadores André Paulo Castanha e Paulino Orso et alli (2010), assim como inúmeros artigos, monografias de conclusão de curso e dissertações de mestrado, resultado do esforço e do trabalho dos pesquisadores da História da Educação no oeste do Paraná.

\section{CONSIDERAÇÕES FINAIS}

Paciência é a condição primária do pesquisador em arquivo. Seguindo os procedimentos da pesquisa acadêmica em identificar a instituição, o arquivo, localizar e selecionar os documentos e decifrar os escritos encontrados, estes são alguns dos desafios que se completam à tarefa de pesquisa em fontes. Ainda é muito precário entre nós o entendimento acerca da importância da preservação de acervos documentais.

No bojo da pesquisa acadêmica, os arquivos e as fontes documentais permitem ao pesquisador atento, encontrar e reconhecer culturalmente a intencionalidade inerente ao seu processo de produção. Ao representarmos o trabalho historiográfico como uma ponte entre o presente e o passado, estabelecemos um equilíbrio adequado entre a localização, à leitura e o emprego das fontes, de uma parte, e a determinação dos problemas historiográficos, a construção e o uso dos esquemas interpretativos. A relação do historiador com os arquivos e as fontes é uma dessas bases, um alicerce fundamental da pesquisa sobre a qual se edifica a pesquisa historiográfica.

Os arquivos escolares, geralmente são depósitos de documentos, nem sempre bem armazenados, que existem graças ao cuidado dos funcionários que pressentem a importância deles. A pesquisa histórica em fontes documentais não constitui apenas a recuperação da informação armazenada, mas a reivindicação do sentido do passado por meio do conhecimento compartilhado. Sabemos das dificuldades em relação ao espaço e às condições técnicas existentes. Entretanto, é necessário o quanto antes que ocorra uma conscientização não somente por parte do Estado, mas também da própria comunidade envolvida para a preservação documental.

A conservação e preservação não consiste somente na coleta, classificação e divulgação dos documentos, mas também no prolongamento da vida útil desses mesmos documentos, a partir de ações que proporcionem condições de armazenamento e uma organização sistematizada. 
As instituições escolares com a existência ou não de arquivos organizadores, tem sob sua responsabilidade, uma gama de arquivos documentais que geram fontes históricas, que são para os pesquisadores da História da Educação parte de sua base de pesquisa. Nesse sentido, não se deve exaltar ingenuamente os arquivos e a objetividade das fontes, mas dar a eles a devida importância. Daí a necessidade da discussão sobre os arquivos e fontes, atentando-se para a legislação específica produzida no âmbito das relações contraditórias entre Estado e sociedade.

\section{REFERÊNCIAS}

BELLOTTO, Heloísa Liberalli. Arquivos Permanentes: tratamento documental. São Paulo: T.A. Queiroz, 1991.

BRASIL. Constituição (1988). Constituição da República Federativa do Brasil: promulgada em 5 de outubro de 1988. Brasília, DF: Senado, 1988.

BRASIL. Lei número 8.159 de janeiro de 1991. Dispõe sobre a política nacional de arquivos públicos e privados e dá outras providencias. Diário Oficial da União. Brasília, DF.

CAMARGO, Célia Reis. Os Centros de Documentação das universidades: tendências e perspectivas: In: Arquivos, patrimônio e memória: trajetórias e perspectivas. São Paulo: UNESP, 1999.

GRAFTON, Anthony. As origens trágicas da erudição: pequeno tratado sobre a nota de rodapé. Campinas: Papirus, 1998.

HOBSBAWM, E. Sobre História. São Paulo: Companhia das Letras, 1998.

LE GOFF, Jaques. História e Memória. Campinas. Ed. Unicamp, 1994.

MIGUEL, Maria Elisabeth Black. Do levantamento de fontes à construção da historiografia: uma tentativa de sistematização. In. LOMBARDI, J. C.; NASCIMENTO, M. I. M. (orgs.). Fontes, História e Historiografia da Educação. Campinas, SP: Autores Associados: HISTEDBR; Curitiba, PR: PUCPR; Palmas, PR: UNICS; Ponta Grossa, PR: UEPG, 2004. p. $111-140$.

ORSO, Paulino José; CASTANHA, André Paulo; SILVA, João Carlos da; MARTIM, Edison; PERES, Claudio Afonso (org.). História da educação: pesquisa e memória histórica. Cascavel: Coluna do saber, 2008.

PAES, Marilena Leite. Arquivo: Teoria e prática. 3a edição. Rio de Janeiro: Fundação Getúlio Vargas, 1997. 
PARANÁ. Decreto no 4129, de 22 de maio de 2001. Consolida as regras constantes no Manual de Comunicação Escrita Oficial do Estado do Paraná. PARANÁ. Instrução Normativa n.o 2, de 19 de maio de 2004. Estabelece os procedimentos para a entrada de acervos arquivísticos públicos no Departamento Estadual de Arquivo Público do Paraná - DEAP.

PARANÁ. Decreto no 5.044, de 29 de junho de 2005. Aprova a 2a edição do Manual de Comunicação Escrita Oficial do Estado do Paraná.

PARANÁ. Decreto no 274, de 07 de março de 2007. Aprovado o Manual de Gestão de Documentos do Estado do Paraná - 3a Edição.

SAVIANI, Dermeval. Instituições de Memória e organizações de acervos para a História das Instituições Escolares. In: SILVA, João Carlos. História da Educação: arquivos, instituições escolares e memória história. Campinas: Alínea, 2013. 